See Article page 379.

\section{Commentary: One for the money, two for the show, delaying the Ross is the way to go!}

\author{
Aaron Eckhauser, MD, MS
}

Hraska and colleagues ${ }^{1}$ present their expert opinion about managing congenital aortic valve disease using a staged operative strategy with the ultimate destination being the Ross operation. The overarching theme is that although the Ross is the best replacement option for aortic valve disease in children, all reparative attempts should be explored to provide for a more durable and successful delayed Ross procedure. Their map begins with an aggressive reparative strategy in the neonatal and infancy periods using controlled surgical techniques to thin leaflets and open commissures while preserving as much native tissue as possible. Early surgical approaches versus interventional techniques can specifically help to preserve native tissue for future operations and provide a more favorable substrate for a subsequent Ross procedure (residual aortic stenosis with left ventricular hypertrophy). Beyond infancy, the authors advocate for reparative aortic techniques designed to create nonrestrictive, tricuspid geometries incorporating as much native leaflet and annular tissue as possible to improve valve durability and the chance for subsequent repair. The authors state that the Ross should be implemented earlier when additional left sided lesions (eg, endocardial fibroelastosis and mitral stenosis) could predispose a patient to worse hemodynamic status and also when repair no longer provides a reasonable chance of success.

The most significant contribution of their work is the amalgamation of decades of experience and expertise

\footnotetext{
From the Division of Cardiothoracic Surgery, Department of Surgery, University of Utah, Salt Lake City, Utah.

Disclosures: The author reported no conflicts of interest.

The Journal policy requires editors and reviewers to disclose conflicts of interest and to decline handling or reviewing manuscripts for which they may have a conflict of interest. The editors and reviewers of this article have no conflicts of interest.

Received for publication March 5, 2021; revisions received March 5, 2021; accepted for publication March 5, 2021; available ahead of print March 10, 2021.

Address for reprints: Aaron Eckhauser, MD, MS, Division of Cardiothoracic Surgery, Department of Surgery, University of Utah, 100 N Mario Capecchi Dr, Suite 2200, Salt Lake City, UT 84113 (E-mail: Aaron.eckhauser@hsc.utah.edu).

J Thorac Cardiovasc Surg 2022;163:385-6

$0022-5223 / \$ 36.00$

Copyright (C) 2021 by The American Association for Thoracic Surgery

https://doi.org/10.1016/j.jtcvs.2021.03.021
}

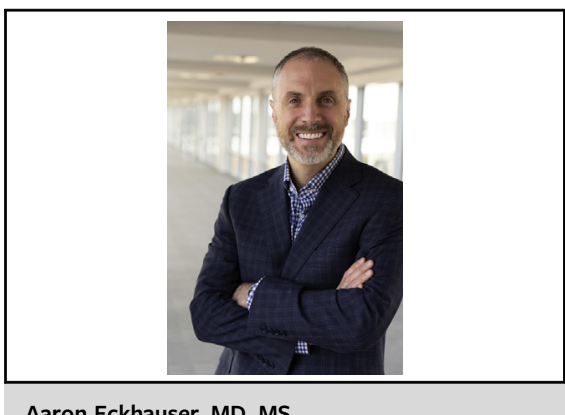

Aaron Eckhauser, MD, MS

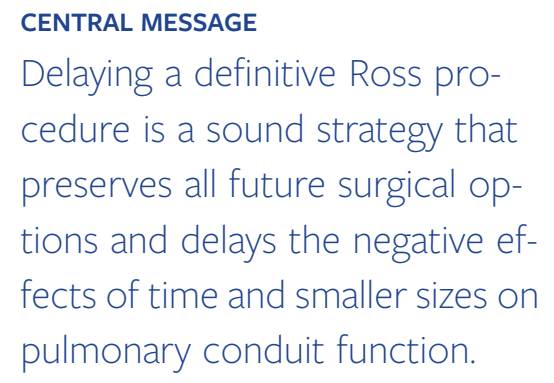

with aortic valve repair, the Ross operation, and the Ross operation after previous aortic valve repair into an effective staged treatment pathway. The authors concur with Buratto and colleagues ${ }^{2}$ that delaying the Ross is favorable because it can benefit the durability of the autograft, but it also delays the time of exposure to a pulmonary conduit until 1 of adequate size can be implanted. The authors speculate why the autograft in a redo field is advantageous; a protective fibrous sheath that forms around the autograft versus the intense inflammation that occurs in a redo field versus a shortened muscular autograft cuff versus inflammatorymediated neovascularization of the autograft itself? Perhaps delaying the Ross until children are older and bigger simply forces a regression back to the basic elements for a successful Ross, including leaving minimal tissue above and below the autograft, supporting both the annulus and sinotublar junction and implanting the autograft deeper within the left ventricular outflow tract.

The single area that the authors do not address is the incidence of worsened autograft integrity in a reoperative field. We have noticed in our own practice that in some multipletime reoperative fields, due to extensive adhesions and dissection, the autograft sinuses are more attenuated with worsened structural integrity, oftentimes requiring external reinforcement or augmentation. Although we do not have long-term data to support this theory yet, I worry that some of these patients with poor autograft integrity will exhibit worsened durability over time. 
I thank the authors for their decades of experience and for sharing their nuanced expertise to help create a successful staged strategy to treat a very complex cohort of children with aortic valve disease.

\section{References}

1. Hraska V, Mitchell ME, Woods RK. Roadmap for Ross procedure: staged strategy. J Thorac Cardiovasc Surg. 2022;163:379-82.

2. Buratto E, Wallace FRO, Fricke TA, Brink J, d'Udekem Y, Brizard CP, et al. Ross procedures in children with previous aortic valve surgery. J Am Coll Cardiol. 2020; 76:1564-73. 